\title{
Absorbsiyonlu (LiBr-su) Nem Alma Sisteminin Isıl Performans Değerlerinin Deneysel Olarak Araştırılması
}

\author{
Ertuğrul CïHAN*1 \\ ${ }^{I}$ Osmaniye Korkut Ata Üniversitesi, Mühendislik Fakültesi, Makine Mühendisliği Bölümü, \\ Osmaniye
}

Geliş tarihi: 23.01.2017 Kabul tarihi: 14.03.2017

$\ddot{\mathbf{O z}}$

$\mathrm{Bu}$ çalışmada, mekanik nem alma sistemlerinin yerine kullanılabilecek, nem alma ve rejenerasyon kolonlarında, daha önce kullanılmamış, polikarbonat dolgu malzemesi kullanılan bir açık sıvı nem alma sisteminin deneysel olarak araştırılmış̧ır. Sıvı desikant olarak kütlece \% $045^{\prime}$ 'lik LiBr-su (Lityum bromürsu) çözeltisi kullanılan sistemde dolgu malzemeleri, $6 \mathrm{~mm}$ kalınlıklarındaki polikarbonat levhaların $30^{\circ}$, $45^{\circ}$ ve $60^{\circ}$ kanal açısı oluşturacak şekilde kesilmesiyle oluşturulmuştur. Sözü geçen kanal açılarının, hava hızının ve sıvı desikant debisinin sistemin nem alma verimine, elektriksel ve isıl performans katsayısına etkisi incelenmiştir.

Anahtar Kelimeler: Sivı desikant, Sivı desikant nem alma sistemi, Polikarbonat dolgu

\section{Experimental Investigation of Thermal Performance Values of Absorption (LiBr-aq) Dehumidification System}

\begin{abstract}
In this study, an open liquid desiccant dehumidification system, using polycarbonate packing material in dehumidification and regenerator columns, has not been used previously, which can be used instead of mechanical dehumidification systems, was experimentally investigated. The packing material of the system, using 45 mass percent LiBr-aq (Lithium bromide-water) solution as desiccant, was formed by cutting polycarbonate sheets $6 \mathrm{~mm}$ thickness to form $30^{\circ}, 45^{\circ}$ and $60^{\circ}$ channel angles. The effect of these channel angles, air velocity and liquid desiccant flow rate on dehumidification efficiency, electrical and thermal coefficient of performance were investigated.
\end{abstract}

Keywords: Liquid desiccant, Liquid desiccant dehumidification system, Polycarbonate packing

\footnotetext{
"Sorumlu yazar (Corresponding author): Ertuğrul CiHAN, ertugrul.cihan@osmaniye.edu.tr
} 


\section{GíRiş}

Artan yaşam standartlarıyla beraber insanların enerji tüketimi de günden güne artmaktadır. Tüketilen enerjinin büyük bir kısmı (yaklaşık \%75) fosil yakıtlardan karşılanmaktadır. Fosil yakitların pek uzak olmayan bir gelecekte tükenecek olması, insanları alternatif enerji kaynaklarına ve enerji tasarrufu arayışlarına yönlendirmektedir. Tüketilen toplam enerjinin büyük bir kısmının iklimlendirme (alan 1sıtmas1/soğutmas1) uygulamalarına harcanması, araştırmacıları bu alanda çalışmaya yönlendirmektedir. Günümüzde yaygın olarak iklimlendirme uygulamalarında kullanılan konvansiyonel buhar sıkıştırmalı soğutma sistemleri enerji tüketimi açısından dezavantajlı sistemlerdir. $\mathrm{Bu}$ sistemlerin kullanımı yüksek enerji tüketiminin yanında, bulundurduğu ozon delici ve yüksek oranda sera etkisi içeren $\mathrm{CFC} / \mathrm{HCFC}$ (kloroflorokarbonlar) gazları sebebiyle çevresel tartışmaları da beraberinde getirmektedir. $\mathrm{Bu}$ sebeple bu sistemlere alternatif olabilecek iklimlendirme sistemleri üzerinde çalışmalar yapılmış ve hala yapılmaktadır [1-2].

Bağıl nemin fazla olduğu bölgelerde, özellikle soğutmada, iç hava konforunun iyileştirilmesinde soğutma işlemi kadar havanın neminin kabul edilebilir bir düzeye getirilmesi yani havadaki gizli ısının da giderilmesi önem taşımaktadır. Konvansiyonel buhar sıkıștırmalı soğutma sistemlerinde havanın gizli 1S1S1, hava buharlaştırıcıda çiğ noktasına kadar soğutularak giderilebilmektedir. Bu uygulama, hem gizli ısının giderilmesine harcanan enerjinin yüksek olmasına, hem de sistem performansının (COP) düşmesine sebep olmaktadır. Bu durum sıcaklık kontrolünden bağımsız nem kontrolünün yapılmasını gerekli kılmaktadır. Havanın gizli 1sısının daha az enerji harcanarak giderilebilmesi ve bağıl nem oranının gerekli düzeye getirilebilmesi için sıvı desikant nem alma sistemleri geliştirilmiştir.

Sıvı desikant nem alma sistemlerinin çalışma prensibi, yüzey buhar basıncı havadan düşük olan bir malzeme kullanılarak, havadaki su buharının soğurulup gizli 1sının duyulur 1sıa dönüştürülmesine dayanır. $\mathrm{Bu}$ şekilde, havadaki gizli 1S1 herhangi bir mekanik enerji harcanmadan ya da çok az miktarda mekanik enerji harcanarak duyulur ısıya çevrilmiş olur. Sıvı desikant nem alma sistemlerinin konvansiyonel buhar sıkıştırmalı soğutma sistemleriyle beraber kullanılması durumunda, \%35'e varan enerji tasarrufu sağlanabileceği [3], sistem performans katsayısının (COP) ise $\% 50$ arttırılabileceği belirtilmiştir [4].

Siv1 desikant nem alma sistemlerinin konvansiyonel buhar sıkıştırmalı soğutma sistemlerine göre oldukça önemli avantajları bulunmaktadır. Birincisi, bu sistemlerin kullanımıyla daha düşük enerji tüketimiyle nem kontrolü sağlanır ve nemi alınmış hava ile iç hava kalitesi önemli ölçüde arttırılır. Bir diğer avantajı ise, daha iyi nem kontrolü yapılarak, nemden dolayı yapılarda meydana gelebilecek küf, mantar ve çürüme gibi olumsuzlukların önüne geçilebilir. Son olarak, siv1 desikant nem alma sistemleri evaporatif soğutma sistemleri ile kullanıldığında CFC gazlarının kullanımı tamamen giderilebilecek, konvansiyonel soğutma sistemleri ile kullanılması durumunda ise CFC kullanımı önemli ölçüde azaltılabilecektir [5]. Bu ve buna benzer diğer avantajlar sıvı desikant nem alma sistemlerinin kullanımını cazip hale getirmektedir.

Bu çalışmada, mekanik nem alma sistemleri yerine kullanilabilecek, nem alma ve rejeneratör kolonlarında dolgu malzemesi olarak, daha önce kullanılmamış, polikarbonat levhalar kullanılan bir siv1 desikant nem alma sisteminin tasarımı ve performans analizi yapılmıştır. Sıvı desikant olarak LiBr-su çözeltisi kullanılan sistemde dolgu kanal açılarının ve akış hızlarının sistemin nem alma verimine, elektriksel ve 1sil performans katsayılarına (COP) etkisi incelenmiştir.

\section{2. ÖNCEKİ ÇALIŞMALAR}

Sıvı desikant nem alma sistemleri üzerine yapılan çalışmalarda genellikle, nem alma veriminin arttırılması, nem alma miktarının arttırılması ve kütle ve ısı transferi performansının iyileştirilmesi üzerinde durulmuştur. 
S1v1 desikant nem alma sistemleriyle ilgili bilinen en erken çalışmalardan biri Lof [6] tarafından yapılmıştır. Çalışmada, sıvı desikant olarak trietilen-glikol kullanılan ve güneş enerjisi ile rejenere edilen nem alma sisteminin tasarımı yapılmış ve deneysel olarak test edilmiştir. Daha sonra yapılan bir başka çalışmada Factor ve Grossman [7], güneş enerjili iklimlendirme sisteminde havadaki nemin alınması ve rejenerasyon için dolgu kolonu tasarlamışlardır. Çalışmada, sistemin farklı çalışma koşulları altında teorik analizini yapmışlardır.

Longo ve Gasparella [8] dolgulu kolonda sıv1 desikantın rejenerasyonu sırasında kolonda kullanılan biçimlendirilmiş (structured) ve rastgele (random) dolgu malzemelerini deneysel olarak karşılaştırmıştır. Çalışmada, rastgele dolgu malzemeleri ile dolu kolonun rejenerasyon performansının biçimlendirilmiş dolgulara oranla \%20-25 daha yüksek olduğu gözlenmiştir. Fakat kolondaki basınç kayıplarına bakıldığında, biçimlendirilmiş dolgu malzemeleri ile dolu kolondaki basınç kaybı diğerine oranla \%65-75 civarında daha düşüktür.

Diğer bir çalışmada Öberg ve Goswami [9], sıvı desikant olarak trietilen glikol kullanılan bir sıv1 desikant nem alma sisteminde gerçekleşen 1sı ve kütle transferini deneysel olarak incelemişlerdir. Çalışmada nem alıcı olarak yine dolgu kolonu kullanmışlar ve iyi bir dolgu kolonunda 1sı ve kütle transferi performanslarının iyi olduğunu ve hatta kolondaki basınç kaybının az olduğunu ortaya koymuşlardır.

Salarian ve arkadaşları [10] ise yaptıkları sayısal çalışmada kolon yüksekliğinin artmasıyla nem alma miktarının arttığını ortaya koymuşlardır. Çalışmada, MATLAB yazılımı yardımıyla sayısal modeller geliştirilmiş ve bu modellerin kabul edilebilirliği deneysel verilerle ispatlanmıştır. Elde edilen sonuçlar, nem alma miktarının nem alma kolonuna giren havanın ve desikant çözeltisinin kütlesel debisinin artmasıyla arttığını fakat giriş havasının sıcaklığının artmasıyla azaldığını göstermiştir.

\section{MATERYAL VE METOT}

\subsection{Materyal}

Çalışmada önerilen sıvı desikant nem alma sistemi, temel olarak, Şekil 1'de görüldüğü gibi hava fanlarından, nem alma ve rejeneratör kolonlarından, sıvı pompalarından ve plakalı 1sı değiştiricilerden oluşmaktadır. Sistemde ölçüm yapabilmek için çeşitli noktalara hız, sıcaklık ve bağıl nem sensörleri yerleştirilmiştir.

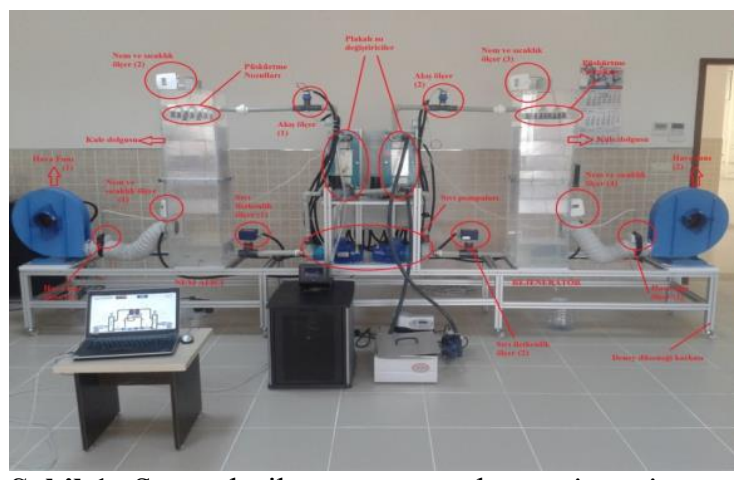

Şekil 1. Sıvı desikant nem alma sistemi ve üzerindeki sensörler

Deney düzeneğinde nem alma ve rejeneratör kolonları şeffaf pleksiglas levhaların, kolon boyutları 30x30x120 cm olacak şekilde yapıştırılmasıyla imal edilmiştir. Kolonlarda kullanılan polikarbonat dolgu malzemesi ise 2x6 m boyutlarındaki büyük polikarbonat levhaların $30^{\circ}$, $45^{\circ}$ ve $60^{\circ}$ kanal açısı oluşturacak şekilde, 30x30 cm boyutlarında kesilmesiyle oluşturulmuştur. Polikarbonat dolgu malzemesinin oluşturulma aşamaları ve kolonların içindeki görünümü Şekil 2'de gösterilmiştir.

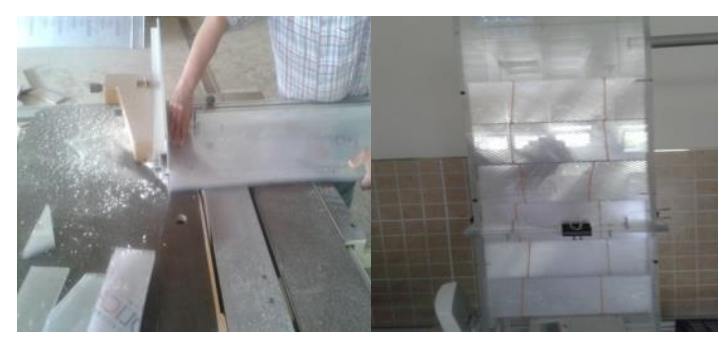

Şekil 2. Polikarbonat levhaların hazırlanması ve kolonlara yerleştirilmesi 


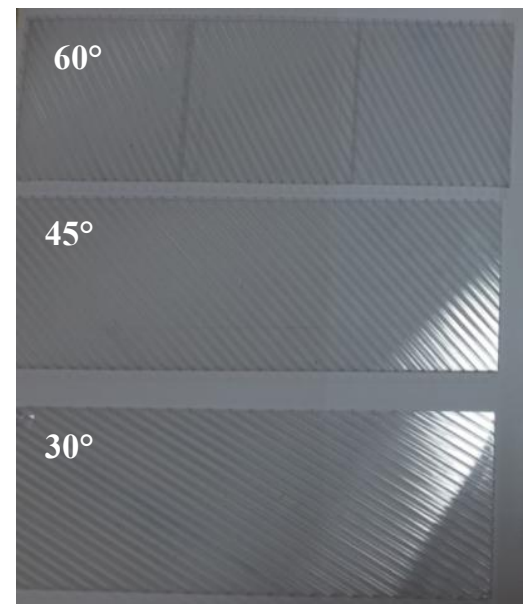

Şekil 3. $30^{\circ}, 45^{\circ}$ ve $60^{\circ}$ kanal açıll polikarbonat levhalar

$30^{\circ}, 45^{\circ}$ ve $60^{\circ}$ kanal açılı $6 \mathrm{~mm}$ kalınlığındaki polikarbonat levhalar Şekil 3 'te gösterilmiştir.

Hazırlanan polikarbonat levhaların yüzey alanları ve gözeneklilik değerleri üç açıdan farklı üçer numune alınıp ölçülmüştür. Polikarbonat dolgu malzemelerinin birim hacimdeki ortalama yüzey alanları ve gözeneklilik değerleri standart sapmalarıyla beraber Çizelge 1'de gösterilmiştir.

Çizelge 1. Polikarbonat dolgu malzemesi ortalama yüzey alanı yoğunluğu ve gözeneklilik değerleri

\begin{tabular}{|l|ccc|}
\hline Kalınlık & \multicolumn{3}{|c|}{$\mathbf{6 ~ m m}$} \\
\hline Kanal Açısı & $\mathbf{3 0}^{\circ}$ & $\mathbf{4 5}^{\circ}$ & $\mathbf{6 0}^{\circ}$ \\
\hline Yüzey alanı yoğunluğu $\left(\mathrm{m}^{2} / \mathrm{m}^{3}\right)$ & $637 \pm 9$ & $650 \pm 3$ & $648 \pm 2$ \\
\hline Gözeneklilik (\%) & $88 \pm 1,3$ & $89 \pm 0,4$ & $89 \pm 0,6$ \\
\hline
\end{tabular}

Şekil 4'te sistem şematik olarak gösterilmiştir. Sistemde nemi alınacak hava nem alma kolonuna hava fanı (1) ile gönderilmektedir. Nem alma kolonuna (Absorber) gönderilen nemli havanın nem alma kolonunda derişik sıvı desikant çözeltisiyle bir miktar nemi alınmaktadır. Havadan bir miktar su buharı alan desikant çözeltisi seyreltik hale geçer. Seyreltik sıvı desikant çözeltisi, (6) noktasındaki sıvı pompası yardımıyla 1sıtılmak üzere 1sı değiştiriciye gönderilir. Sıv1 desikant çözeltisi sıcaklığı bir miktar arttırılarak rejeneratör (Desorber) kolonuna gelir ve burada (3) noktasından hava fanı yardımıyla kolona gönderilen hava ile çözeltiden bir miktar su buharı giderilir. İçerisinden su buharı alınan fakat hala yüzey buhar basıncı yüksek olan çözelti, yüzey buhar basıncının düşürülebilmesi için (5) noktasındaki sıvı pompası ile soğutulmak üzere 1s1 değiştiriciye gönderilir. Is1 değiştiriciden çıkan çözelti tekrar kullanılmak üzere nem alma kolonuna gönderilir ve bu şekilde çevrim tamamlanır.

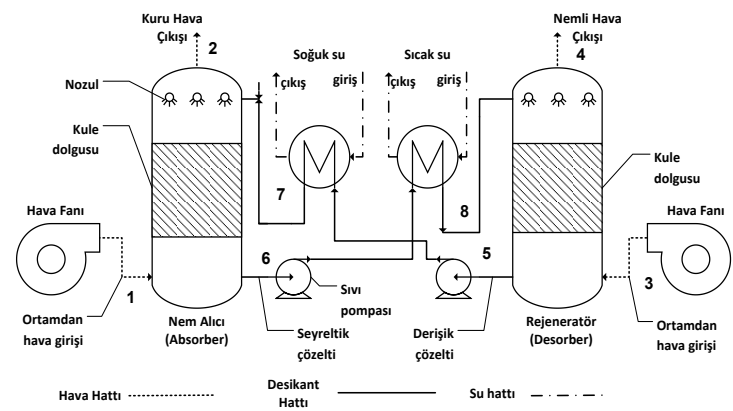

Şekil 4. Sıvı desikant nem alma sistemi şematik görünümü

\subsection{Metot}

Sistemde kolon girişleri ve çıkışlarında havadaki su buharının doyma basıncı Antonie denklemi ile bulunmuştur:

$\ln P_{w}^{s a t}=A-\frac{B}{T+C}$

Burada, $A=16,3872, B=3885,7$ ve $C=230,17$ sabit katsayılar olup su buharı için Antonie parametreleridir [11]. Havanın mutlak nemi ise aşağıdaki eşitlik ile tanımlanmıştır:

$\omega=0,622 \frac{P_{w}^{s a t}}{P_{T^{-}} P_{w}^{s a t}}$

Burada $P_{T} \quad(\mathrm{kPa})$, havanın toplam basincinı göstermektedir. Nem alma kolonunun nem alma verimi ise Eşitlik 3 ile hesaplanmıştır [12]:

$\eta_{a b}=100 \frac{\omega_{1}-\omega_{2}}{\omega_{1}-\omega_{\text {sat }}}$ 
Eşitlik 3'te $\omega_{1}(\mathrm{~kg} / \mathrm{kg})$ ve $\omega_{2}(\mathrm{~kg} / \mathrm{kg})$ sırasıyla havanın nem alma kolonu girişindeki ve çıkışındaki mutlak nemini göstermektedir. $\omega_{\text {sat }}(\mathrm{kg} / \mathrm{kg})$ ise LiBr-su desikant çözeltisi ile dengede olan havanın mutlak nemi olup, desikant çözeltisinin bulunduğu sicaklıktaki buhar basıncı kullanılarak Eşitlik 2 ile hesaplanmıştır. Birim zamanda kazanılan buharlaşma 1sı enerjisi ise Eşitlik 4 ile hesaplanmıştır.

$\dot{Q}_{b}=\dot{m}_{a}\left(\omega_{1}-\omega_{2}\right)\left(h_{1}-h_{2}\right)$

Eşitlik 4'te $\dot{m}_{a}(\mathrm{~kg} / \mathrm{s})$ havanın nem alma kolonu içindeki kütlesel debisini, $h_{1}(\mathrm{~kJ} / \mathrm{kg})$ ve $h_{2}(\mathrm{~kJ} / \mathrm{kg})$ ise sırasıyla havanın nem alma kolonu girişindeki ve çıkışındaki entelpilerini göstermektedir. Sistemde birim zamanda harcanan 1 sil enerji ise Eşitlik 5 ile belirlenmiştir:

$\dot{Q}_{h}=\dot{m}_{h w} * c p_{h w} *\left(T_{h w, g}-T_{h w, \varsigma}\right)$

Burada, $\dot{m}_{h w} \quad(\mathrm{~kg} / \mathrm{s})$ 1sitma suyunun $1 \mathrm{~s} 1$ değiştiricideki kütlesel debisini, $c p_{h w}(\mathrm{~kJ} / \mathrm{kg} . \mathrm{K})$ 1sıtma suyunun ortalama özgül 1sısını, $T_{h w, g}\left({ }^{\circ} \mathrm{K}\right)$ ve $T_{h w, c ̧}\left({ }^{\circ} \mathrm{K}\right)$ ise sirasiyla 1 sitma suyunun $1 \mathrm{~s} 1$ değiştiriciye giriş ve çıkış sıcaklıklarını göstermektedir.

Sistemin 1sıl performans katsayısı Eşitlik 6 ile hesaplanmıştır:

$C O P_{t h}=\frac{\dot{Q}_{b}}{\dot{Q}_{h}}$

Elektriksel performans katsayısı ise Eşitlik 7 ile bulunmuştur:

$C O P_{e}=\frac{\dot{Q}_{b}}{\dot{W}_{e}}$

Eşitlik 7'de $\dot{W}_{e}(\mathrm{~kW})$ birim zamanda harcanan elektrik enerjisini göstermektedir.

Önerilen sıv1 desikant nem alma sisteminde nem alma verimi, 1sil ve elektriksel performans katsayıları deneysel veriler temel alınarak hesaplandığından sistemde belirsizlik analizi yapılması gerekmektedir.

Çizelge 2'de ölçüm aletlerinin ölçüm hassasiyeti değerleri verilmiştir. $\mathrm{Bu}$ hassasiyet değerlerine göre nem alma veriminin belirsizliği Eşitlik 8 ile hesaplanmıştır [13]:

Çizelge 2. Sistemdeki ölçüm aletleri ve hassasiyet değerleri

\begin{tabular}{|l|c|}
\hline \multicolumn{1}{|c|}{ Tip } & Hassasiyet \\
\hline VAISALA HMT120 & $\begin{array}{c} \pm \% 1,5 \text { Bağ1l Nem, } \pm 0,2^{\circ} \mathrm{C} \\
\text { Sicaklık }\end{array}$ \\
\hline KIMO-CTV210 & $\pm \% 0,3$ \\
\hline CF Signet Capteur 515 & $\pm \% 0,5$ \\
\hline K tipi 1s1-çift & $\% 0,4^{\circ} \mathrm{C}$ \\
\hline
\end{tabular}

$\frac{\delta \eta_{A b}}{\eta_{A b}}=\sqrt{\left(\frac{\delta \omega_{1}}{\omega_{1}}\right)^{2}+\left(\frac{\delta \omega_{2}}{\omega_{2}}\right)^{2}+\left(\frac{\delta \omega_{\text {sat }}}{\omega_{\text {sat }}}\right)^{2}}$

Burada $\omega_{1}$ ve $\omega_{2}$ değerleri ölçülen sicaklık, bağıl nem ve basınç değerlerine bağlı oldukları için $\delta \omega_{1}$ ve $\delta \omega_{2}$ belirsizlik değerleri, Çizelge 2'de 1 . satırda bulunan hassasiyet değerleri temel alınarak hesaplanmıştır. $\omega_{\text {sat }}$ değeri ise $\mathrm{K}$ tipi 1 sıl çift ile ölçülen sıvı desikant çözeltisi sıcaklığına ve çözelti konsantrasyonuna bağlı olduğundan $\delta \omega_{\text {sat }}$ belirsizlik değeri, Çizelge 2'de 4. satırdaki hassasiyet değeri kullanılarak hesaplanmıştır.

Aynı şekilde $\dot{Q}_{b}$ ve $\dot{Q}_{h}$ değerlerinin belirsizlikleri sırasıyla Eşitlik 9 ve 10 ile hesaplanmıştır.

$\frac{\delta \dot{Q}_{b}}{\dot{Q}_{e v}}=\sqrt{\left(\frac{\delta \omega_{1}}{\omega_{1}}\right)^{2}+\left(\frac{\delta \omega_{2}}{\omega_{2}}\right)^{2}+\left(\frac{\delta h_{1}}{h_{1}}\right)^{2}+\left(\frac{\delta h_{2}}{h_{2}}\right)^{2}+\left(\frac{\delta m_{a}}{m_{a}}\right)^{2}}$

$\frac{\delta \dot{Q}_{h}}{\dot{Q}_{h}}=\sqrt{\left(\frac{\delta T}{T_{h w, g}}\right)^{2}+\left(\frac{\delta T}{T_{h w, \zeta}}\right)^{2}+\left(\frac{\delta m_{h w}}{m_{h w}}\right)^{2}}$

Isıl ve elektriksel performans katsayılarının belirsizliği Eşitlik 9 ve 10 'da hesaplanan $\dot{Q}_{b}$ ve $\dot{Q}_{h}$ değerlerinin belirsizliğinden yola çıkılarak aşağıdaki eşitliklerle belirlenmiştir. 


$$
\begin{aligned}
& \frac{\delta C O P_{t h}}{C O P_{t h}}=\sqrt{\left(\frac{\delta \dot{Q}_{e v}}{\dot{Q}_{e v}}\right)+\left(\frac{\delta \dot{Q}_{h}}{\dot{Q}_{h}}{ }^{2}\right.} \\
& \frac{\delta C O P_{e}}{C O P_{e}}=\sqrt{\left(\frac{\delta \dot{Q}_{e v}}{\dot{Q}_{e v}}\right)}
\end{aligned}
$$

Absorber nem alma verimi $\left(\eta_{a b}\right)$ bağıl hatası $\% 3,7$, $\dot{Q}_{b}$ ve $\dot{Q}_{h} 1$ sı transferi değerlerinin bağıl hataları sirasiyla \%2,3, \%3,7, COP th ve $\quad C O P_{e} \quad 1$ sil performans katsayılarının bağıl hataları ise sırasıyla \%4,8, \%3,4 olarak hesaplanmıştır.

\section{BULGULAR ve TARTIŞMA}

Önerilen LiBr-su sivı nem alma sisteminde, $6 \mathrm{~mm}$ kalınlığındaki $30^{\circ}, 45^{\circ}$ ve $60^{\circ}$ üç ayrı kanal açılı polikarbonat levhalar kullanılarak deneyler gerçekleştirilmiştir. Yapılan deneylere ait bazı parametreler Çizelge 3'te gösterilmiştir.

\begin{tabular}{|c|c|}
\hline Parametre adı & $\begin{array}{c}\text { Ölçülen/Belirlenen } \\
\text { Değer }\end{array}$ \\
\hline Siv1 desikant & $\begin{array}{r}\text { Kütlece \%45 LiBr } \\
\text { Çözeltisi }\end{array}$ \\
\hline Dolgu yüksekliği, cm & 60 \\
\hline Ortalama hava kütlesel debisi, $\mathrm{m}^{3} / \mathrm{h}$ & $400,680,1000$ \\
\hline Ortalama desikant kütlesel debisi, kg/s & $1,42,1,85$ \\
\hline Hava fanı dönme frekansı, $\mathrm{Hz}$ & $20,34,50$ \\
\hline Sıvı pompası dönme frekansı, $\mathrm{Hz}$ & 20,26 \\
\hline $\begin{array}{l}\text { Soğutma suyu ortalama giriş/çıkış } \\
\text { sıcaklıkları }\end{array}$ & $14 / 22^{\circ} \mathrm{C}$ \\
\hline $\begin{array}{l}\text { Isıtma suyu ortalama giriş̧/çıkış } \\
\text { sıcaklıkları }\end{array}$ & $59,1 / 50,2^{\circ} \mathrm{C}$ \\
\hline $\begin{array}{l}\text { Ortalama çözelti sıcaklığ (nem alma } \\
\text { kolonu) }\end{array}$ & $28,7^{\circ} \mathrm{C}$ \\
\hline Ortalama çözelti sıcaklığı (rejeneratör) & $45,8^{\circ} \mathrm{C}$ \\
\hline
\end{tabular}

Çizelge 3. Deneysel parametreler

Nem alma verimine $30^{\circ}, 45^{\circ}$ ve $60^{\circ}$ kanal açıl polikarbonat dolgu malzemeleri için hava ve sıv1 debilerinin etkisi Şekil 5 'te gösterilmiştir. $30^{\circ}$ ve $45^{\circ}$ kanal açılarında LiBr-Su çözeltisinin hızının artışının nem alma verimi üzerine etkisi belirgin olmasına rağmen $60^{\circ}$ 'lik kanal açılı dolgu malzemesinde bu gözlenememiştir. Buna neden olarak $60^{\circ}$ 'lik kanal açısının hava-sıvı temas yolu ya da temas süresi diğer açllara göre az olması gösterilebilir. $30^{\circ}$ kanal açısının sağladığı, hava ile sıvının temas yolunun dolayısıyla sürenin uzunluğu sistemin nem alma verimini olumlu bir şekilde etkilemiştir. En yüksek nem alma verimi $\% 74,3$ ile $30^{\circ}$ kanal açılı dolgu malzemesinde gözlemlenmiştir.
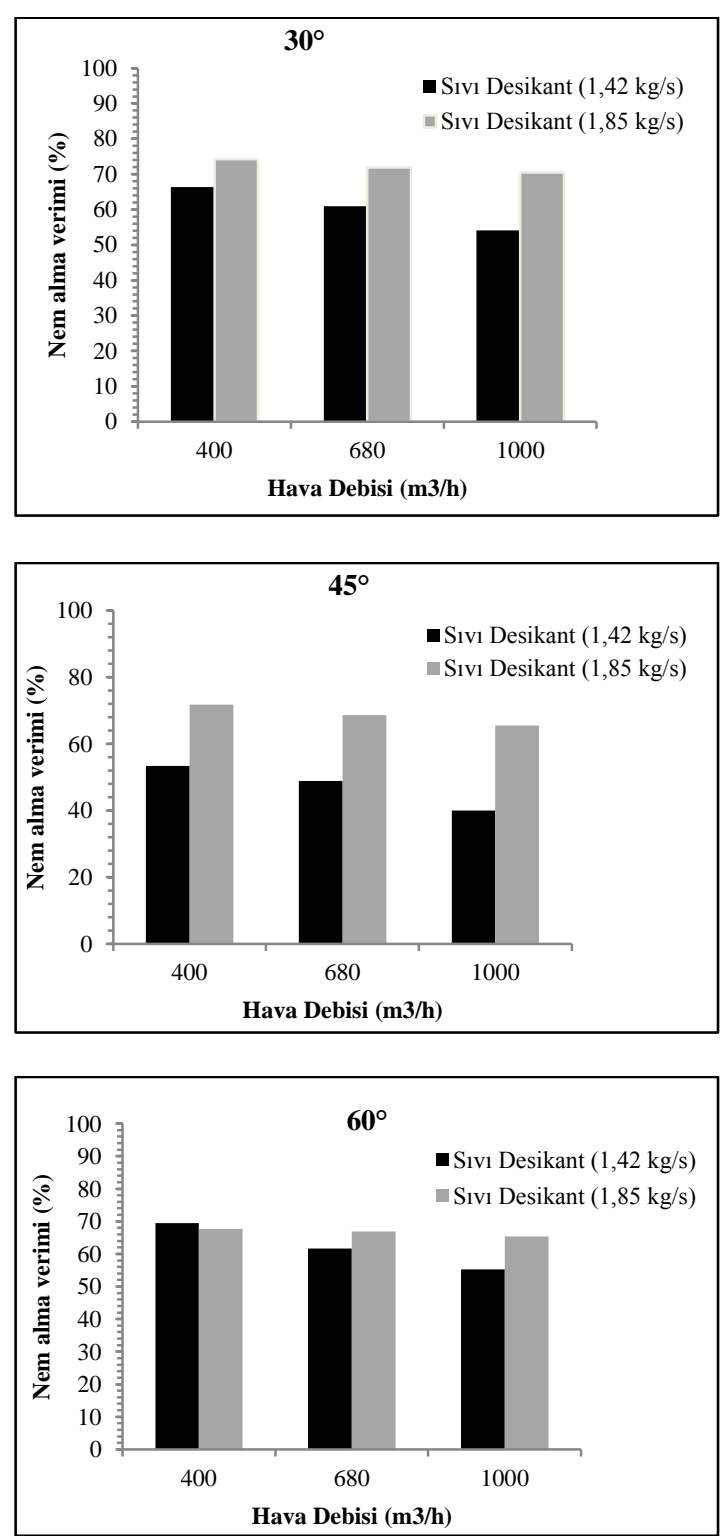

Şekil 5. Nem alma veriminin kanal açılarıyla, sıvı ve hava hızlarıyla değişimi 

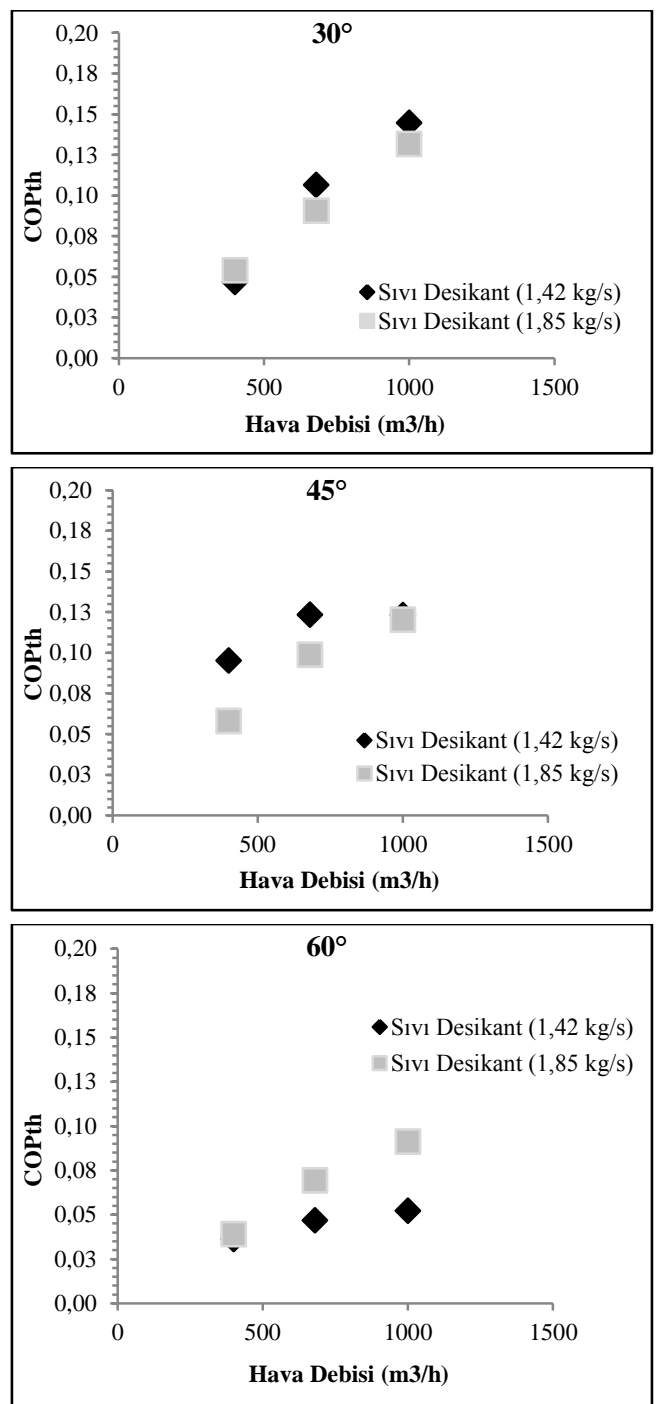

Şekil 6. Isıl COP değerlerinin kanal açılarıyla, sıvı ve hava hızlarıyla değişimi

Şekil (6), $30^{\circ}, 45^{\circ}$ ve $60^{\circ}$ kanal aç1lı dolgu malzemeleri için hesaplanan isıl performans katsayısı değerlerinin, hava ve sıvı hılarıyla değişimini göstermektedir. Maksimum isıl COP değeri 0,14 olarak $30^{\circ} \mathrm{kanal}$ açısında, $1000\left(\mathrm{~m}^{3} / \mathrm{s}\right)$ hava debisi ve $1,85(\mathrm{~kg} / \mathrm{s})$ siv1 debisi ile elde edilmiştir.

$6 \mathrm{~mm}$ 'lik polikarbonat dolgu malzemesi için hava akış hızı, sıvıı akış hızı ve dolgu malzemesinin kanal açılarının elektriksel performans katsayısı değerlerine olan etkisi Şekil 7'de gösterilmektedir. Maksimum elektriksel COP değeri 1,52 olarak, 1sıl COP değerinde olduğu gibi $30^{\circ}$ kanal açısında, $1000\left(\mathrm{~m}^{3} / \mathrm{s}\right)$ hava debisi ve $1,85(\mathrm{~kg} / \mathrm{s})$ sıv1 debisi ile elde edilmiştir. $60^{\circ}$ kanal açısı için ise elektriksel COP değeri genelde 1,0 altında elde edilmiştir. Elektriksel COP değerinin 1,0 üzerinde olması, sistemin birincil enerji kaynaklarını verimli bir şekilde kullandığını göstermektedir.
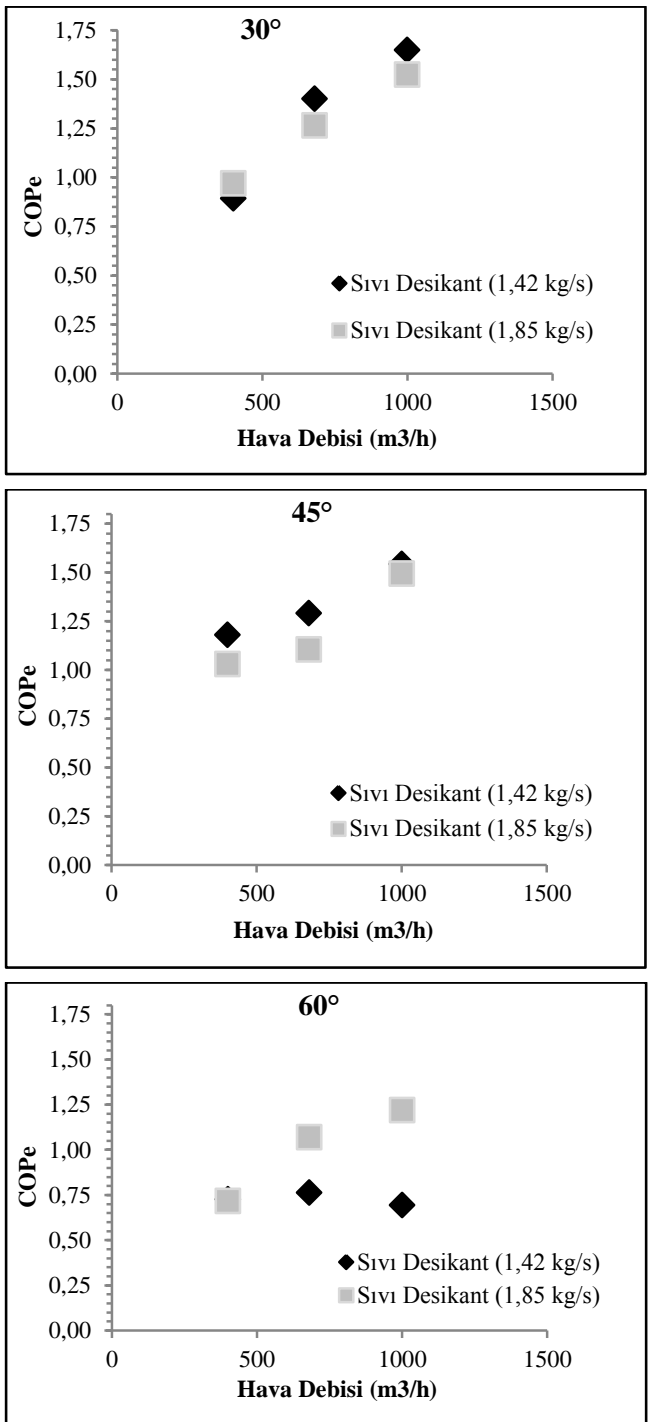

Şekil 7. Elelektriksel COP değerlerinin kanal açılarıyla, hava ve sıvı hızlarıyla değişimi 


\section{SONUÇ}

Bu çalışmada, kolonlarda dolgu malzemesi olarak, daha önce kullanılmamış, polikarbonat dolgu malzemesi kullanılan bir LiBr-su açık sıvı desikant nem alma sisteminin tasarımı yapılarak, hava ve sıvı desikant çözeltisi akış hızlarının ve dolgu kanal açılarının sistem performansına etkisi incelenmiştir.

Grafiklerden de anlaşılabileceği gibi sistem için belirlenen performans kriterleri, yüzey alanları birbirine yakın olması sebebiyle dolgu kanal açılarından çok fazla etkilenmemektedir. Buna karşın sıvı desikantın hızının artması kütle transferi katsayısını arttırdığından özellikle ısıl COP ve elektriksel COP değerlerinde önemli derecede artış sağlamıştır. Sıvı hızının artması $30^{\circ}$ ve $60^{\circ}$ kanal açıll dolgu malzemelerinde nem alma verimini de iyileştirmiş̧ir. Hava hızının artması ise nem alma veriminde, hava-sivi desikant temas süresinin azalmasından dolayı, bir azalışa sebep olmuştur. Buna karşın elektriksel COP ve isıl COP değerlerinde, hava hızının artması, önemli bir iyileşme sağlamıştır.

Elde edilen sonuçlara bakıldığında açık sıvı desikant nem alma sisteminin performansının, sivı hızlarından ve hava hızlarından yüksek oranda etkilendiği görülebilmektedir. Bu sebeple sayısal analizlerle ve hesaplamalı akışkanlar dinamiği (CFD) analizleriyle optimum hava ve sıvı akış hizları belirlenip sistem performans1 daha da arttırılabilecektir. Bunun yanında daha yüksek yüzey alanlarına sahip polikarbonat levhalar kullanılarak, sistemin teorik analizleriyle optimum dolgu yüksekliği ve kanal açısı belirlenerek sistem performansı daha da iyileştirilebilecektir.

\section{TEŞEKKÜR}

$\mathrm{Bu}$ çalışma, 1001-Bilimsel ve Teknolojik Araştırma Projelerini Destekleme Programı kapsamında TÜBİTAK tarafindan 114M151 no'lu proje ile desteklenmektedir.

\section{KAYNAKLAR}

1. Xu, M., Duan, Y., Xin, F., Huai, X., Li, X., 2014. Design of an Isopropanol-acetoneHydrogen Chemical Heat Pump with Exothermic Reactors in Series, Applied Thermal Engineering, 71, p. 445-449.

2. Zhai, X. Q., Wang, R. Z., 2009. A Review for Absorbtion and Adsorbtion Solar Cooling Systems in China, Renewable and Sustainable Energy Reviews, 13, p. 1523-1531.

3. Yadav, Y. K., Kaushik, S. C., 1991. Psychrometric Techno-economics Assessment and Parametric Studies of Vapor-Compression and Solid/liquid Desiccant Hybrid Solar Space Conditioning System, Heat Recovery Systems \& CHP, 11, p. 563-572.

4. Khalid Ahmed, C. S., Gandhidasan, P., AlFarayedhi, A. A., 1997. Simulation of a Hybrid Liquid Desiccant Based Air-conditioning System, Applied Thermal Engineering, 17, p. $125-134$,

5. Desiccant Cooling: State-of-the-Art Assesment" Erişim adresi: http://web.ornl.gov/sci/ees/etsd/btric/eere_resea rch_reports/thermally_activated_technologies/d esiccant_systems/performance_evaluations/nrel _tp_254_4147/nrel_tp_254_4147.pdf Erişim Tarihi: 22.11.2016.

6. Lof, G. O. G., 1955. Cooling with solar energy, Congress on solar energy, p. 171-189, TucsonArizona.

7. Factor, H. M., Grossman, G. A., 1980. Packed Bed Dehumidifier/regenerator for Solar Air Conditioning with Liquid Desiccants, Solar Energy, 24, p. 541-550.

8. Longo, A. G., Gasparella A., 2009. Experimental Analysis on Desiccant Regeneration in a Packed Column with Structure and Random Packing, Solar energy, 83, p. 511-521.

9. Öberg, V., Goswami, D. Y., 1998. A Review of Liquid Desiccant Cooling, Advances in Solar Energy, 12, p. 431-470.

10. Salarian, H., Ghadamian, H., Assadi K. M., Ataei, A., 2011. An Experimental and Modeling Study of a Dehumidification Tower, 
International Journal of the Physical Sciences, 6, 12, p. 2852-2860.

11. Poling, B. E., Prausnitz, J. M., O’Connell, J. P., 2001. The Properties of Gases and Liquids, $5^{\text {th }}$ Edition, Appendix A, McGraw-Hill, New York.

12. Koronaki, I. P., Christodoulaki, R. I., Papaefthimiou, V. D., Rogdakis, E. D., 2013. Thermodynamic Analysis of a Counter Flow Adiabatic Dehumidifier with Different Liquid Desiccant Materials, Applied Thermal Engineering, 50, p. 361-373.

13. ASME PTC 19.1-2013, 2014. Test Uncertainty: Performance Test Codes, The American Society of Mechanical Engineers, New York. 
